\title{
Mental health and burden in mothers of children with congenital Zika syndrome during COVID-19 pandemic
}

\section{Gabriela Lopes Gama 1}

iD https://orcid.org/0000-0002-7352-6711

Bruna Milena da Silva 2

iD https://orcid.org/0000-0003-4357-1180

Mariana Balbino da Silva 3

iD https://orcid.org/0000-0001-5333-3536

Rayssa Vieira Brandão Ferreira 4

iD https://orcid.org/0000-0003-4924-2556

\author{
Jousilene de Sales Tavares 5 \\ iD https://orcid.org/0000-0002-4040-9164 \\ Adriana Melo 6 \\ (iD) https://orcid.org/0000-0002-8575-544X
}

1-6 Instituto de Pesquisa Professor Joaquim Amorim Neto (IPESQ). Rua Salvino Oliveira Neto, 87. Santo Antônio. Campina Grande, PB, Brasil. CEP: 58.402-040. E-mail: gabilopes_@hotmail.com

\begin{abstract}
Objectives: to evaluate burden, frequency of anxiety and signs and symptoms of depression in mothers of children with congenital Zika syndrome (CZS) during the COVID-19 pandemic and the social isolation period.

Methods: this is a cross-sectional study conducted with mothers who care for their children with CZS. The data were collected by an online form with questions regarding mother's socioeconomic conditions and questions related with Zarit burden scale and Beck's inventories on depression and anxiety. Spearman's correlation tests and multiple regression analyzes were performed to assess factors related to mothers' burden and mental health.

Results: 41 mothers were evaluated, 51.2\% had mild burden, $39 \%$ had minimal anxiety and $73.2 \%$ did not have signs and symptoms of depression. Negative correlations were observed between levels of burden and maternal schooling $(p=0.01)$, presence of signs and symptoms of anxiety and receiving financial aid $(p<0.04)$ as well as the presence of signs and symptoms of anxiety and having children with seizures history $(p=0.03)$.

Conclusion: despite the risk of their children again being victims of an epidemic virus, mothers who care for their children with CZS did not present serious mental health impairments.
\end{abstract}

Key words Zika virus infection, Cost of illness, Social isolation, Anxiety, Depression

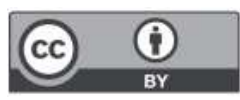




\section{Introduction}

Women infected by Zika virus during pregnancy, whose children were later diagnosed with congenital Zika syndrome (CZS), live until today the consequences of the Zika virus epidemic, described between 2015 and 2016. ${ }^{1}$ According to data from the Ministry of Health of Brazil, between 2015 and 2018, 3474 confirmed cases of CZS were registered and countless other cases still remained under investigation. ${ }^{2}$

The natural history of CZS is not yet fully clarified, however, it is known that it courses on a wide spectrum of neurological signs such as microcephaly, changes in muscle tone, persistence of primitive reflexes, irritability, visual abnormalities, and clonus. 3,4 These impairments require constant care that, in general, is provided by the parents, more specifically by mothers of these children. 5

In the early 2020, in the face of the outbreak of the COVID-19 pandemic, scientists warned which groups were considered vulnerable and at higher risk of death if infected by the new virus. ${ }^{6}$ Among these groups are individuals with chronic comorbidities, such as children with CZS who often present recurrent pneumonias, dysphagia, difficult-to-control seizures, and severe motor impairment. ${ }^{7,8}$ In addition to these comorbidities, unfavorable socioeconomic conditions may increase the vulnerability of these children to infections.9,10 Thus, during the COVID-19 pandemic, children with CZS and their mothers experience a second potentially fatal viral outbreak, and the children are at eminent risk of being doubly victimized.

Besides to the vulnerable situation, the need for social isolation as a measure to prevent COVID-1911 infections, it has drastically changed the routine of mothers of children with CZS. The weekly routine of therapies and frequent medical appointments were replaced by extended stays at home, challenges of family coexistence, and socioeconomic uncertainties generated by the pandemic. 12

Given to this context, the present study aimed to evaluate the burden and frequency of signs and symptoms of anxiety and depression in mothers of children with congenital Zika syndrome (CZS) during the COVID-19 pandemic and the period of social isolation. With this, we sought to understand how these women experienced the first months of the COVID-19 pandemic, which may serve as a basis for psychosocial assistance programs for families of children with CZS. The hypothesis initially raised by the authors was that the COVID-19 pandemic and social isolation significantly affected the mental health of mothers of children with CZS, assessed through the levels of burden and frequency of signs and symptoms of anxiety and depression.

\section{Methods}

This was an exploratory, observational, crosssectional study conducted in July 2020, a period in which most Brazilian States were experiencing strict social isolation. This study was conducted with mothers of children assisted by the Support Center for Children with Microcephaly linked to the Instituto de Pesquisa Professor Joaquim Amorim Neto (IPESQ) (Research Institute), based in the city of Campina Grande/PB. This institution has been providing assistance to pregnant women and children infected by Zika virus since 2015 .

The study population was composed by mothers of children with confirmed or presumed diagnosis of CZS.13 The sample was selected by convenience considering mothers who agreed to participate in the study voluntarily. The inclusion criteria were mothers of children diagnosed with CZS and the exclusion criteria were mothers who did not have access to Internet. Figure 1 shows the flowchart of the sample selection.

Initially, mothers who fit the eligibility criteria were contacted and invited to be part of the study. Those who accepted the invitation received the link to access an online form, by message app. Data collection was carried out by using Google Forms digital tool, in order to avoid any physical contact between mothers and the researchers, complying with the recommendations for social distancing by the World Health Organization (WHO).

The data collection form was composed of a series of questions that should be answered individually. Initially, general and demographic data of participants were registered, such as age, schooling, marital status, city where they live, and number of people with whom they live. In addition, questions about the daily life of these women during COVID19 pandemic and their social isolation were addressed. In the second step of the form, questions regarding the Zarit Burden Scale (ZBS), 14,15 Beck Anxiety Inventory (BAI), and Beck Depression Inventory (BDI-II) were presented.16

The ZBS is an instrument that allows to evaluate caregiver's objective and subjective burden. It is composed of 22 questions referring to caregivers' feelings in different situations, answers can range from zero (Never) to four (Almost always). Thus, the total score of this scale can vary between zero and 88 , scores below 20 are related to a light burden or 


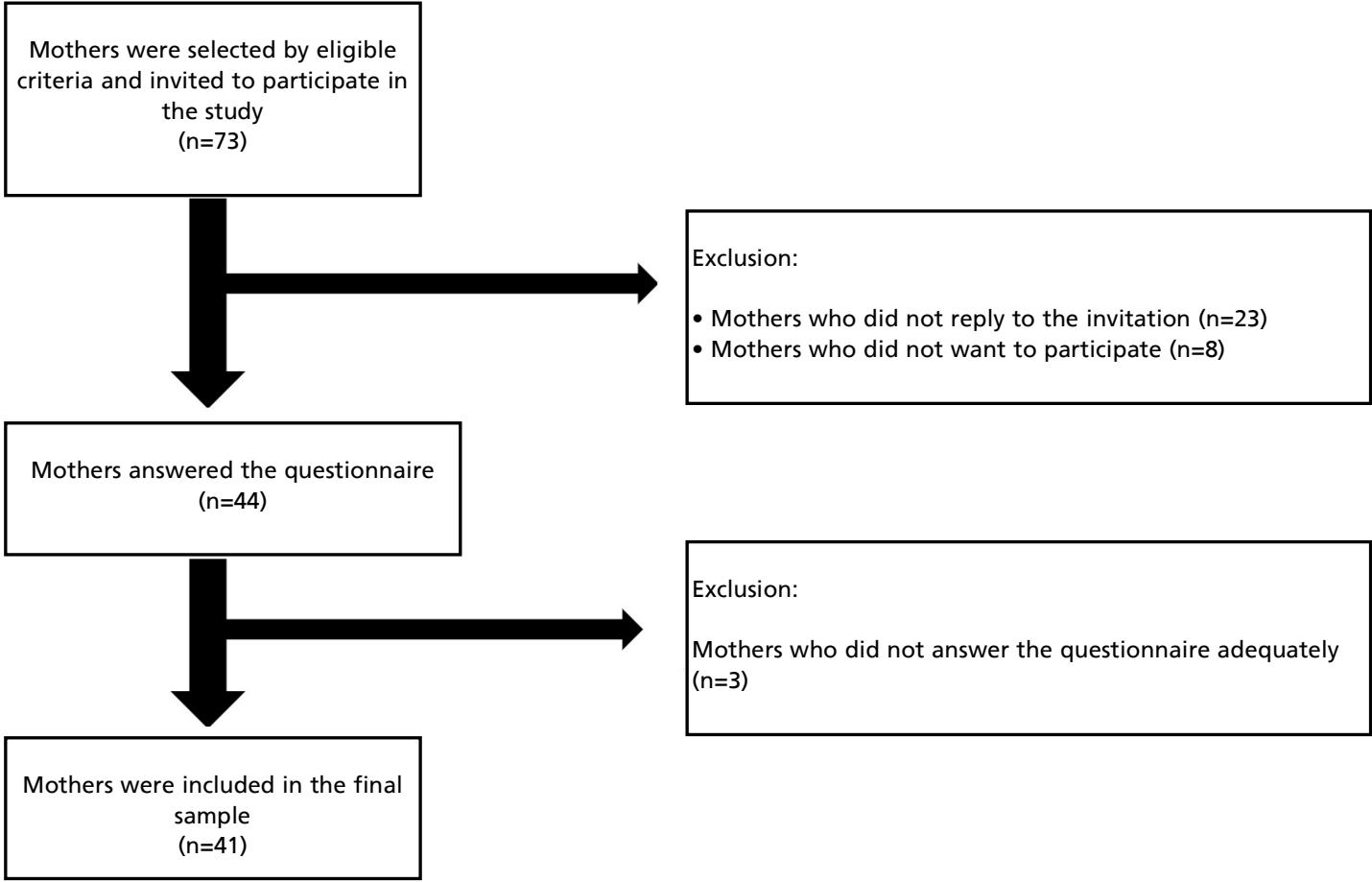

no burden, scores between 21 and 40 to a moderate burden, between 41 and 60 to a moderate to severe burden, and above 61 to severe burden. ${ }^{17}$

The BAI is a scale that aims to measure intensity signs and symptoms of anxiety. It is composed of a list of 21 feelings that should be classified considering the intensity of their presentation in the last week. Thus, each feeling should be rated on a scale between zero (Absolutely not) and three (Severely), totaling a final score ranging from 20 to 63 points. According to this score, anxiety level can be classified as minimal (scores between 0 and 7), mild (scores between 8 and 15), moderate (scores between 16 and 25), and severe (scores between 26 and 63). 18 The BDI-II aims to assess the presence of signs and symptoms of depression. It is composed of 21 objective questions that must be scored on a scale between zero and three. Scores between 16 and 31 indicate mild depression, between 32 and 47 moderate depression, and greater than 47 severe depression. 19

In addition to maternal information, from the IPESQ clinical records, the children's general data were registered, such as weight, height, and head circumference at birth and before the recommendation of social isolation (February-March/2020), the child's level of motor impairment was classified by means of the Gross Motor Function Classification Scale (GMFCS) 20 and occurrence of comorbidities such as seizures, gastrostomy, and number of medications used.

In order to evaluate the level of burden and presence of signs and symptoms of anxiety and depression among mother of children diagnosed with CZS during the COVID-19 pandemic, we initially performed the descriptive data analysis by measures of central tendency and dispersion for quantitative variables, such as the mothers and children's age, number of people with whom they live, and the total score on the ZBS, BAI, and BDI- II scales. In addition, for categorical variables such as marital status, schooling, and online form questions, absolute and relative frequencies were calculated.

Variables referring to maternal general and sociodemographic characteristics, behavior during social isolation, and the child's general health condi- 
tions were coded as binary variables 1 (Yes) or 0 (No). Next, Spearman's correlation coefficient was calculated between the dependent variables (predictive variables) and the final scores of the ZBS, BAI, and BDI- II. Finally, three independent multiple regression analyses were performed considering as dependent variables those that presented a significance level $<0.20$ in Spearman's correlation tests and the final ZBS, BAI, and BDI- II scores. All the tests were performed using MedCalc software, version 17.9.7 (MedCalc Software, Ostend, Belgium), and a significance level of 0.05 was maintained.

The research was guided by the ethical principles described in Resolution number 466/12 and 510/16 of the national health council of Brazil, approved by research ethics committee of the Centro de Ensino Superior e Desenvolvimento (CESED) (Center for Higher Education and Development) in June, 2020 (CAE: 32781620.2.0000.5175). Before the data collection, the mothers who were part of the sample virtually signed the informed consent form.

\section{Results}

The sample was composed of 41 mothers with ages ranging from 20 to 42 years old $(29.36 \pm 6.24)$. Of these, $34.1 \%(n=15)$ were married, $40.9 \%(n=18)$ had completed high school, 52.3\% $(n=23)$ had a family income of one minimum wage and $84.1 \%$ $(n=37)$ received financial aid to supplement their family income, either from government programs or third parties. As for housing conditions, 47.7\% $(n=21)$ of the mothers lived in their own home.

Children with CZS whose mothers were evaluated had ages ranging from 39 to 58 months (52.4 \pm 4.14$)$, of which $72.2 \%(\mathrm{n}=32)$ had microcephaly at birth and $90.9 \%(\mathrm{n}=40)$ had severe motor impairment, being classified in level V of GMFCS. The general characteristics of mothers who took part in this study and their children are presented in Table 1.

As regards to facing the COVID-19 pandemic, all mothers reported having access to products to prevent infections of new coronavirus, such as alcohol gel and masks; $73.2 \%(n=30)$ reported not feeling informed about the care to be taken to avoid contagion and the most cited sources of information was the internet $(85.4 \%, \mathrm{n}=35)$ and television $(73.2 \%, \mathrm{n}=38)$.

During the period of social isolation, $82.9 \%$ $(n=34)$ of mothers reported leaving the house a few times, when necessary, respecting social distancing and taking the recommended care. It was also reported that this behavior was adopted by other people who resided with $51.2 \%(n=21)$ of investigated mothers.

Most mothers (97.6\%, $\mathrm{n}=420)$ were very concerned about possible infection of COVID-19 with their children with CZS. Many mothers also reported that their life was extremely affected by the COVID-19 pandemic in terms of family relationships $(29.3 \%, \mathrm{n}=12)$, emotional $(46.3 \%, \mathrm{n}=19)$ and financial conditions $(24.4 \%, \mathrm{n}=10)$, and physical aspects $(34.1 \%, \mathrm{n}=14)$.

Regarding the support received for care of their child with CZS during social isolation, $65.9 \%$ $(n=27)$ of the mothers reported a reduction in their support network and $29.3 \% \quad(n=12)$ reported receiving a reasonable support.

When asked about their mental health, $63.4 \%$ $(n=26)$ of mothers reported that their mental health was good before the pandemic. With pandemic onset and required social isolation, $9.8 \%(n=4)$ of these women reported no change in their mental health, $7.3 \%(n=3)$ reported that their mental health was greatly affected, and $46.3 \%(n=19)$ reported that their mental health was somewhat affected. Before the pandemic, $36.6 \%(\mathrm{n}=15)$ of the mothers considered their mental health not well, of these $17.1 \%$ $(n=7)$ reported worsening in their mental health with the pandemic, $17.1 \%(\mathrm{n}=7)$ considered their mental health was the same and $2.4 \%(\mathrm{n}=1)$ considered their mental health had improved.

When asked about their most striking feeling in the last week, the most mentioned feelings by investigated mothers were anxiety $(63.4 \%, \mathrm{n}=26)$, fear $(63.4 \%, n=26)$, and stress $(61.0 \%, n=25)$. Table 2 presents the feelings most commonly mentioned by mothers who were part of the present study.

The mothers' level of burden was assessed by means of the ZBS that had scores ranging from 0 to 66 points (median=27 and $I Q=19.75$ to 37 ). The level of burden was rated as mild in $51.2 \%(n=21)$ of the mothers, moderate in $19.5 \%(\mathrm{n}=8)$ of the mothers, severe in $2.4 \%(n=1)$ of the mothers and absent in $26.8 \%(n=11)$ of the mothers. A negative correlation was observed between the score of this scale and maternal schooling level $(\mathrm{rho}=-0.38$, $p=0.01$ and $\mathrm{CI} 95 \%=0.08$ to 0.61 ). This correlation was maintained after multiple regression analysis.

The anxiety level was measured using the BAI, with total score ranging from 0 to 54 points (median=14, IQ=4-22.25). Of the mothers assessed, $39 \%(\mathrm{n}=16)$ had minimal anxiety, $17.1 \%(\mathrm{n}=7)$ mild anxiety, $22 \%(n=9)$ moderate anxiety, and $22 \%(n=9)$ severe anxiety. The BAI score showed a negative correlation by receiving financial aid from the government (rho $=-0.31, p=0.04$, CI95\% $=-0.57$ to - 
Mothers' general characteristics who took place in the present study and their children with . Campina Grande, 2020

\begin{tabular}{|c|c|c|c|c|}
\hline Characteristics & $\mathbf{N}$ & $\%$ & Range & $\overline{\mathrm{X}} \pm \mathrm{SD}$ \\
\hline \multicolumn{5}{|l|}{ Mother } \\
\hline Age, years & & & $20-42$ & $29.36 \pm 6.24$ \\
\hline Lives with partner, YES & 31 & 70.4 & & \\
\hline \multicolumn{5}{|l|}{ Schooling } \\
\hline Illiterate & 1 & 2.3 & & \\
\hline Graduated or not from Elementary school & 16 & 36.4 & & \\
\hline Graduated from High School & 18 & 40.9 & & \\
\hline Graduated or not from Higher Education & 9 & 20.5 & & \\
\hline \multicolumn{5}{|l|}{ Family Income* } \\
\hline$<1$ wage & 17 & 38.6 & & \\
\hline$\geq 1$ wage $<3$ minimum wages & 25 & 56.9 & & \\
\hline$\geq 3$ minimum wages & 2 & 4.5 & & \\
\hline Receives financial aid from the government, YES & 33 & 75 & & \\
\hline Receives financial aid from family members or third parties, YES & 27 & 61.4 & & \\
\hline \multicolumn{5}{|l|}{ Living conditions } \\
\hline Own home & 21 & 47.7 & & \\
\hline Rent & 11 & 25 & & \\
\hline Others & 12 & 27.3 & & \\
\hline Number of rooms at home & & & 4-11 & $6.1 \pm 1.4$ \\
\hline Number of people with whom you live & & & $2-6$ & $3.6 \pm 1.03$ \\
\hline \multicolumn{5}{|l|}{ Child } \\
\hline Sex, Male & 27 & 61.4 & & \\
\hline Child's age, months & & & $39-58$ & $52.4 \pm 4.1$ \\
\hline \multicolumn{5}{|l|}{ Cephalic perimeter } \\
\hline At birth & & & $23-34$ & $30.1 \pm 2.1$ \\
\hline Currently & & & $37-49.5$ & $42.13 \pm 2.9$ \\
\hline \multicolumn{5}{|l|}{ BMI } \\
\hline At birth & & & $8.17-18$ & $13.1 \pm 1.7$ \\
\hline Currently & & & $12.1-23.2$ & $16 \pm 2.5$ \\
\hline \multicolumn{5}{|l|}{ GMFCS } \\
\hline Level I & 2 & 4.9 & & \\
\hline Level II & 1 & 2.4 & & \\
\hline Level III & 0 & - & & \\
\hline Level IV & 1 & 2.4 & & \\
\hline Level V & 37 & 90.2 & & \\
\hline \multicolumn{5}{|l|}{ Occurance of comorbidities } \\
\hline Seizures, YES & 13 & 31.7 & & \\
\hline Takes two or more medication, YES & 17 & 41.5 & & \\
\hline Gastrostomy, YES & 4 & 9.8 & & \\
\hline
\end{tabular}

$\mathrm{BMI}=$ body mass index; GMFCS = Gross Motor Function Classification Scale; $\mathrm{N}=$ number of participants; $\mathrm{SD}=\mathrm{Standard}$ Deviation.

* At the time of data collection, the Brazilian minimum wage was $R \$ 1,045.00$ reais 


\begin{tabular}{|c|c|c|c|c|}
\hline \multirow[t]{2}{*}{ The most striking feeling in the past days } & \multicolumn{2}{|c|}{ Yes } & \multicolumn{2}{|c|}{ No } \\
\hline & $\mathrm{n}$ & $\%$ & $\mathrm{n}$ & $\%$ \\
\hline Anxiety & 26 & 63.4 & 15 & 36.6 \\
\hline Exhaustion & 19 & 46.3 & 22 & 53.7 \\
\hline Stress & 25 & 61 & 16 & 39.0 \\
\hline Impotence & 10 & 24.4 & 31 & 75.6 \\
\hline Fear & 26 & 63.4 & 15 & 36.6 \\
\hline Sadness & 15 & 36.6 & 26 & 63.4 \\
\hline Desire to take own's life & 1 & 2.4 & 40 & 97.6 \\
\hline
\end{tabular}

$0.01)$ and third parties (rho $=-0.4, p=0.01$, CI95\% $=-$ 0.63 to -0.11 ), as well as with the history of seizures of the child with CZS ( $\mathrm{rho}=-0.33, p=0.03$, CI95\%= 0.58 to -0.027$)$. This correlation was maintained after multiple regression analysis.

Finally, the BDI-II total score ranged from 0 to $50($ median $=9, I Q=3.75-15.25)$ when $73.2 \%(n=30)$ of the mothers showed no signs or symptoms of depression, $22 \%(\mathrm{n}=9)$ showed signs and symptoms of mild depression, $2.4 \%(\mathrm{n}=1)$ of moderate depression and $2.4 \%(n=1)$ of severe depression. This score did not show any correlation with the other variables analyzed.

Table 3 presents the results of Spearman's correlation tests between the predictive variables referring to the characteristics of the mothers and children as well as the behavior adopted by the families during the period of social isolation and the ZBS, BAI, and BDI- II scores. Table 4 presents the results of the multiple regression analyses.

\section{Discussion}

In March 2020, strict social distancing measures were implemented in Brazil as a way to contain the spread of new coronavirus and avoid the collapse in health systems, following WHO recommendations. ${ }^{21}$ These measures, coupled with rapid dissemination of a potentially lethal virus, were often associated with psychological changes such as hysteria, irritability, anguish, depression, and anxiety, in addition to the feeling of imprisonment and lack of control.22

These changes and their short- and long-term repercussions have worried specia-lists 22,23 and can be potentiated by lack of knowledge about the natural history of the disease, perception of risk factors, financial losses, and inappropriate information disseminated by social media.
Feelings such as anxiety, fear, and stress were reported by more than half of the mothers investigated in this study. These results may reflect the psychological changes related to the COVID-19 pandemic and social isolation, coupled with the impacts of caring for a child with severe neurological impairments often associated with comorbidities. $3,4,8$ Previous studies show that caregivers of children with CZS mental health is particularly vulnerable for the need of intense care, difficulties with specialized healthcare and the lack of knowledge about the natural history of the disease.24 These particularities seem to have become an even greater challenge in face of social isolation required by COVID-19 pandemic and reduction of support network, reported by most of mothers in the present study, and may have reflected the feelings described by the mothers.

Contrary to the hypothesis initially raised, most mothers investigated presented a mild level of burden, minimal anxiety, and absence of signs and symptoms of depression. These findings may be related to two factors: first, the remote follow-up of children with CZS by a multi-professional team at the support center from which the sample of the present study was recruited. This remote intervention network may have represented an important support network for mothers and a space to dialogue between mothers and professionals, which may have positively influenced these women's mental health. Second, the selection of participants by convenience may have led mothers who experienced greater repercussions of pandemic on their mental health to choose not to participate in the research, despite the researchers' invitation to mothers whose children were followed by the IPESQ.

The demand of suspending the health services considered as non-essential during the COVID-19 
Table 3

Spearman's correlation analysis between predictive variables and total score of the Zarit burden scale, Beck's anxiety inventory and Beck's depression inventory. Campina Grande, 2020.

\begin{tabular}{|c|c|c|c|}
\hline Characteristics & ZBS & BAI & BDI- II \\
\hline \multicolumn{4}{|l|}{ Mother's Characteristics } \\
\hline Age, years & -0.08 & -0.05 & -0.18 \\
\hline Lives with a partner, YES & 0.09 & 0.14 & $0 . .13$ \\
\hline Schooling: Graduated from High school, YES & $-0.38 * t$ & 0.17 & $027+$ \\
\hline Family Income, $<1$ wage, YES & $-0.24 \div$ & -0.019 & 0.05 \\
\hline Receives financial aid from government, YES & 0.05 & $-0.31 *$ & $-0.23 \div$ \\
\hline Receives financial aid from Family member or third parties, YES & $0.26 !$ & $-0.4 *+$ & -0.14 \\
\hline Rooms at home, YES & 0.05 & -0.15 & $-0.22 \div$ \\
\hline Lives with $>4$ people, YES & 0.11 & -0.06 & 0.19 \\
\hline \multicolumn{4}{|l|}{ Child's Characteristics } \\
\hline Microcephaly at birth, YES & $0.3 !$ & 0.035 & 0.12 \\
\hline GMFCS level V, YES & 0.01 & -0.18 & -0.14 \\
\hline Seizures, YES & -0.01 & $-0.33 *$ & $-0.29 !$ \\
\hline Takes two or more medications, YES & 0.13 & 0.08 & 0.09 \\
\hline Gastrostomy, YES & $0.24 \div$ & 0.11 & 0.07 \\
\hline \multicolumn{4}{|l|}{ Social isolation during the pandemic } \\
\hline Maintaining social isolation by mother, YES & 0.07 & 0.001 & 0.013 \\
\hline Support to care for child with CZS during social isolation, YES & 0.11 & -0.01 & $0.23+$ \\
\hline Reduction of support network, YES & $-0.26+$ & 0.02 & 0.102 \\
\hline
\end{tabular}

${ }^{*} p<0.05, \downarrow p<0.2$

Subtitles: $\mathrm{CZS}=$ Congenital Zika syndrome, GMFCS= Gross Motor Function Classification Scale, ZBS= Zarit burden scale. $\mathrm{BAI}=$ Beck anxiety inventory and BDI-II= Beck depression inventory II.

\section{Table 4}

\begin{tabular}{|c|c|c|c|c|}
\hline Variables & Coefficient & SEM & $\mathbf{T}$ & $p$ \\
\hline \multicolumn{5}{|l|}{ ZBS Score } \\
\hline Schooling: Graduated from High school, YES & 13.89 & 4.81 & 2.88 & 0.006 \\
\hline \multicolumn{5}{|l|}{ BAI Score } \\
\hline Seizures, YES & -9.26 & 4.39 & -2.11 & 0.04 \\
\hline \multicolumn{5}{|l|}{ Receives financial aid from family members or } \\
\hline third parties, YES & -11.17 & 4.15 & -2.69 & 0.011 \\
\hline Receives financial aid from government, YES & -10.01 & 4.76 & -2.10 & 0.042 \\
\hline
\end{tabular}


pandemic, led health professionals to implement remote interventions in order to maintain the healthcare. ${ }^{25}$ In this context, remote follow-up emerges as a pillar of telemedicine capable of meeting the immediate needs of the COVID-19 pandemic, encompassing strategies such as message exchange through applications, phone calls, educational videos, and real-time video calls. ${ }^{25}$ The mothers in the present study were part of a support center that implemented a remote multidisciplinary follow-up since the second month after the suspension of their face-to-face activities. This assistance was provided by professionals in nursing, physiotherapy, psychology, occupational therapy, and speech therapists, who had been providing in-person assistance to the children before the isolation. This fact may also have favored the success of children's remote monitoring on the mothers' mental health.

Another point worth mentioning is the change in mothers' and children's routines during social isolation. Exhaustive therapeutic routines and transportation difficulties in receiving therapeutic care for the child 5,26 were described in previous studies as difficulties faced by mothers of children with CZS. These routines were interrupted by the social distancing measures required by the COVID-19 pandemic, which may have allowed mothers evaluated to stay at home with their families for more time and thus, share daily tasks and anguish, with the consequence of reducing the level of burden. The data from the present study, however, only partially support this hypothesis.

Besides the lethality and the lack of efficient treatment, the COVID-19 pandemic has as a particularity, the technological moment experienced worldwide and the intense intercontinental interconnection. If, on one hand, this fact favored communication between researchers and governments aiming development of vaccines and health policies, on the other hand, it can be a source of dissemination of fake news and panic that generates confusion and misinformation. 27 These negative points can explain the mothers' report of not feeling informed about COVID-19, even with access to means of communication, such as television and Internet, and hygiene products to avoid contamination. This self-report can also be related to divergences between government policies to confront the pandemic 28 and the mothers' difficulties in critically interpreting the information conveyed in the media.

The data from the present study show that the only factor related to maternal burden was the schooling level, when mothers who did not graduate from high school showed higher levels of burden.
These findings may reflect the unfavorable socioeconomic conditions and less economic and social support of mothers with low schooling levels. This hypothesis, however, should be viewed with caution considering the lower proportion of women who did not graduate from high school in the sample of the present study. This imbalance regarding the mothers' schooling can be explained by the nature of data collection instrument, which required literacy skills or help from others to fill it out.

Linked to health uncertainties, COVID-19 also brought financial instability, especially in middleand low-income families. ${ }^{27}$ This was also the part of population most affected by Zika virus epidemic, when a higher prevalence of cases was described in areas with precarious living conditions and in lowincome families. 29 Thus, the association between financial aid, either from the government or third parties, with maternal anxiety levels can be justified by the fear of financial losses. These findings corroborate with negative correlation between financial factors, such as the difficulty to pay basic expenses, and mental health of mothers of children with CZS, were previously described. 30

The only comorbidity that was related to maternal anxiety levels was seizures. This is a common clinical sign in children with CZS that is often related to severe brain impairment. 8 This association may be related to the mothers' fear of running out of medication and/or financial resources to acquire them, or even difficulties with medical care. This is because the children's growth and weight gain during period of social isolation could contribute to increased frequency of seizures, requiring specialized medical consultations that became even more difficult during the pandemic, especially in the public network.

Despite the relevance of the findings presented in present study, some limitations must be considered: First the cross-sectional nature of the study that makes it impossible to determine the direct effects of pandemic on mothers' mental health, moreover, this methodology does not make it possible to identify variations in levels of burden and signs and symptoms of anxiety and depression presented in mothers during the course of pandemic. Second, online data collection may have discouraged the participation of mothers with unfavorable socioeconomic conditions, with difficulties in handling technological instruments, and/or with higher levels of burden. Third, all mothers recruited are followed by a research and healthcare institute focused on children with CZS that maintained their activities even during social isolation period, a fact that may 
limit generalizations.

Although, most mothers caring for their children with CZS considered their mental and physical health, financial and emotional conditions to be affected by the COVID-19 pandemic, most mothers showed mild burden, minimal anxiety, and no signs and symptoms of depression. These findings may be related to the remote follow-up measures performed by healthcare professionals, as well as the dynamic nature of general state of these mothers during the pandemic. It is suggested that future studies should be conducted involving mothers from different regions in Brazil, through qualitative approaches in order to measure more specifically experiences lived by these women throughout the COVID-19 pandemic.

\section{References}

1. WHO. Screening, assessment and management of neonates and infants with complications associated with Zika virus exposure in utero 2016 [Available from: https://apps.who.int/iris/bitstream/handle/10665/204475/W HO ZIKV MOC 16.3 eng.pdf;jsessionid=C870DD37A0 9252368149E2B2A221D889? sequence $=1$.

2. Brasil MdS. Boletim Epidemiológico. Monitoramento integrado de alterações no crescimento e desenvolvimento relacionadas à infecção pelo vírus Zika e outras etiologias infecciosas, até a Semana Epidemiológica 30 de 2018. [Brazil, Ministry of Health. Integrated monitoring of growth and developmental changes related to Zika virus infection and other infectious etiologies by Epidemiological Week 30 of 2018.] Brazil, Ministry of Health.; 2018 [Available from: http://portalarquivos2.saude.gov.br/ images/pdf/2018/setembro/11/2018-047.pdf.

3. Saad T, PennaeCosta AA, de Goes FV, de Freitas M, de Almeida JV, de Santa Ignez LJ, et al. Neurological manifestations of congenital Zika virus infection. Childs Nerv Syst. 2018; 34 (1): 73-8

4. Moura da Silva AA, Ganz JS, Sousa PD, Doriqui MJ, Ribeiro MR, Branco MD, et al. Early Growth and Neurologic Outcomes of Infants with Probable Congenital Zika Virus Syndrome. Emerg Infect Dis. 2016; 22 (11) 1953-6

5. Freitas PSS, Soares GB, Mocelin HJS, Lamonato L, Sales CMM, Linde-Arias AR, et al. How do mothers feel? Life with children with congenital Zika syndrome. Int J Gynecol Obst. 2020; 148 (Suppl. 2): 20-8.

6. The L. Redefining vulnerability in the era of COVID-19. Lancet. 2020; 395 (10230): 1089.

7. Leal MC, Van der Linden V, Bezerra TP, de Valois L, Borges ACG, Antunes MMC, et al. Characteristics of Dysphagia in Infants with Microcephaly Caused by Congenital Zika Virus Infection, Brazil, 2015. Articles from Emerging Infectious Diseases. 2017; 23 (8): 1253-9.

\section{Authors' contribution}

Gama GL, Silva BM: idea conception, data collection, data analysis, project management, original manuscript draft, and final writing review. Silva MB, Ferreira RVB: data collection, data analysis, and final draft review. Tavares JS and Melo A: data analysis, function acquisition, project management, and final draft review. All authors approved the final version of the article.

8. Pessoa A, van der Linden V, Yeargin-Allsopp M, Carvalho M, Ribeiro EM, Van Naarden Braun K, et al. Motor Abnormalities and Epilepsy in Infants and Children With Evidence of Congenital Zika Virus Infection. Pediatrics. 2018; 141 (Suppl. 2): S167-79.

9. Moore CA, Staples JE, Dobyns WB, Pessoa A, Ventura CV, Fonseca EB, et al. Characterizing the Pattern of Anomalies in Congenital Zika Syndrome for Pediatric Clinicians. JAMA Pediatr. 2017; 171 (3): 288-95.

10. Melo A, Gama GL, Da Silva Junior RA, De Assuncao PL, Tavares JS, Da Silva MB, et al. Motor function in children with congenital Zika syndrome. Dev Med Child Neurol. 2019; 62 (2): 221-6.

11. Kuwahara K, Kuroda A, Fukuda Y. COVID-19: Active measures to support community-dwelling older adults. Travel Med Infect Dis. 2020: 101638.

12. Fegert JM, Vitiello B, Plener PL, Clemens V. Challenges and burden of the Coronavirus 2019 (COVID-19) pandemic for child and adolescent mental health: a narrative review to highlight clinical and research needs in the acute phase and the long return to normality. Child Adolesc Psychiatry Ment Health. 2020; 14: 20.

13. Center for Diseasse Control and Prevention C. Understanding Zika Virus Test Results 2019 [Available from: https://www.cdc.gov/zika/hc-providers/testing-forzikavirus.html?CDC_AA_refVal=https $\% 3 \mathrm{~A} \% 2 \mathrm{~F} \% 2 \mathrm{Fwww} . c d c$. gov $\% 2$ Fzika $\% 2$ Fhc-providers $\% 2$ Ftestresults.html.

14. Seng BK, Luo N, Ng WY, Lim J, Chionh HL, Goh J, et al. Validity and reliability of the Zarit Burden Interview in assessing caregiving burden. Ann Acad Med Singap. 2010; 39 (10): 758-63.

15. Taub A, Andreoli SB, Bertolucci PH. Dementia caregiver burden: reliability of the Brazilian version of the Zarit caregiver burden interview. 2004; 20 (2): 372-6. 
16. Vignola RC, Tucci AM. Adaptation and validation of the depression, anxiety and stress scale (DASS) to Brazilian Portuguese. J Affect Disord. 2014; 155: 104-9.

17. Albayrak I, Biber A, Caliskan A, Levendoglu F. Assessment of pain, care burden, depression level, sleep quality, fatigue and quality of life in the mothers of children with cerebral palsy. J Child Health Care. 2019; 23 (3): 483-94.

18. Wolfe-Christensen C, Fedele DA, Kirk K, Phillips TM Mazur T, Mullins LL, et al. Degree of external genital malformation at birth in children with a disorder of sex development and subsequent caregiver distress. J Urol. 2012; 188 (4 Suppl.): 1596-600

19. Unsal-Delialioglu S, Kaya K, Ozel S, Gorgulu G Depression in mothers of children with cerebral palsy and related factors in Turkey: a controlled study. Int J Rehabil Res. 2009; 32 (3): 199-204.

20. Palisano R, Rosenbaum P, Bartlett D, M. L. GMFCS - E \& R Gross Motor Function Classification System Expanded and Revised 2007 [Available from: https://www.canchild.ca/system/tenon/assets/attachments/000/000/058/original/GMFCS-ER English.pdf.

21. WHO WHO. Coronavirus disease (COVID-19) advice for the public 2020 [Available from: https:/www.who.int/ emergencies/diseases/novel-coronavirus-2019/advice-forpublic.

22. Qiu J, Shen B, Zhao M, Wang Z, Xie B, Xu Y. A nationwide survey of psychological distress among Chinese people in the COVID-19 epidemic: implications and policy recommendations. Gen Psychiatr. 2020; 33 (2): e100213.

23. Carvalho Aguiar Melo M, de Sousa Soares D. Impact of social distancing on mental health during the COVID-19 pandemic: An urgent discussion. Int J Soc Psychiatry. 2020:20764020927047.

Received on November 18, 2020

Approved on February 3, 2021
24. Bailey DB, Jr., Ventura LO. The Likely Impact of Congenital Zika Syndrome on Families: Considerations for Family Supports and Services. Pediatrics. 2018; 141 (Suppl 2): S180-S7.

25. Mann DM, Chen J, Chunara R, Testa PA, Nov O. COVID19 transforms health care through telemedicine: Evidence from the field. J Am Med Inform Assoc. 2020; 27 (7): 11325.

26. Sa S, Galindo CC, Dantas RS, Moura JC. [Family dynamics of children with congenital Zika syndrome in Petrolina, Pernambuco State, Brazil]. Cad Saúde Pública. 2020; 36 (2): e00246518

27. Castro-de-Araujo LFS, Machado DB. Impact of COVID-19 on mental health in a Low and Middle-Income Country. Ciên Saúde Coletiva. 2020; 25 (Suppl. 1): 2457-60.

28. Marson FAL, Ortega MM. COVID-19 in Brazil. Pulmonol. 2020; 26 (4): 241-4.

29. Souza WV, Albuquerque M, Vazquez E, Bezerra LCA, Mendes A, Lyra TM, et al. Microcephaly epidemic related to the Zika virus and living conditions in Recife, Northeast Brazil. BMC Public Health. 2018; 18 (1): 130.

30. Kotzky K, Allen JE, Robinson LR, Satterfield-Nash A, Bertolli J, Smith C, et al. Depressive Symptoms and Care Demands Among Primary Caregivers of Young Children with Evidence of Congenital Zika Virus Infection in Brazil. J Dev Behav Pediatr. 2019; 40 (5): 344-53. 